\title{
POR UM HABITAR POÉTICO - O ENCONTRO DA FOTOGRAFIA COM A POESIA DE MANOEL DE BARROS
}

\author{
Through a Poetic Dwell - an Confluence of Photography With the \\ Manoel de Barros's poetry \\ Por un Habitar Poético - Posibilidad de Revelar la Experiencia con la Fotografía y \\ Poesía de Manoel de Barros
}

VALERIA AMORIM DO CARMO

\begin{abstract}
Resumo: A escrita aqui apresentada tem como propósito apresentar o relato de uma experiência feita na companhia de autores e suas obras durante o ano de 2015 com o intuito de trazer um pouco de luz à inquietação que trago comigo e que pretendo que seja minha guia: pensar a fotografia como possibilidade reveladora das relações diversas do homem com a terra, ou seja, sua geograficidade. Esta foi a proposta apresentada no V Seminário Nacional do Grupo de Pesquisa Geografia Humanista Cultural SEGHUM. Foi um ano de leituras e reflexões e porque não dizer de angústias, que me fizeram pensar, principalmente após a leitura do texto Poeticamente o homem habita de Heidegger, se a questão originária não estaria na linguagem poética antes de partir para pensar a fotografia uma vez que penso a fotografia como linguagem, como arte, como possibilidade poética. Neste caminhar, além da fotografia me deparei também com as palavras do poeta Manoel de Barros que, juntas fotografia e poesia, me ajudam nesta aproximação com o desvelar de um habitar poético. Assim, este texto apresenta um pouco desta caminhada.
\end{abstract}

Palavras-chave: Fotografia; Manoel de Barros; Linguagem poética; Geograficidade.

Resumen: La escritura que aquí se presenta tiene como objetivo presentar el informe de una experiencia hizo en la compañía de autores y su trabajo durante el año 2015 con el fin de aportar un poco de luz a la preocupación que tengo conmigo y yo quiero que sea mi guía: pensar la fotografía como revelando posibilidad de diferentes relaciones entre el hombre y la tierra, es decir, su geographicity. Esta fue la propuesta hecha en el Seminario Nacional de la Quinta Humanista Cultural Grupo de Investigación en Geografía - SEGHUM. Fue un año de lecturas y reflexiones y por qué no decirlo angustia, que me hizo pensar, sobre todo después de leer el texto Poetically hombre habita Heidegger, la pregunta originalmente no estaría en lenguaje poético antes de empezar a pensar en la foto una vez Creo que la fotografía como lenguaje, como arte, como posibilidad poética. En este caminar, así como la fotografía también se encontró con las palabras del poeta Manoel de Barros, junto fotografía y la poesía que me ayude en este enfoque con la presentación de una vivienda poética. Por lo tanto, este artículo presenta algunos de este caminar.

Palabras-clave: Fotografía; Manoel de Barros; Lenguaje poético; Geographicity.

Abstract: The writing presented here aims to present the report of an experience made within the authors company and their work during the year 2015 in order to bring a little light to the concern that I have with me and I want to be my guide: think photography as revealing possibility of different relationships between man and the earth, that is, its geographicity. This was the proposal made at the Fifth National Seminar of the Research Group Geography Cultural Humanist - SEGHUM. It was a year of readings and reflections and why not say anguish, that made me think, especially after reading the Heidegger's text Poetically man dwells, the question originally would not be in poetic language before starting to think the photo once I think photography as language, as art, as poetic possibility. In this walk, as well as photography also came across the words of the poet Manoel de Barros, together photography and poetry help me in this approach with the unveiling of a poetic dwelling. Thus, this paper presents some of this walk.

Keywords: Photography; Manoel de Barros; Poetic language; Geographicity.

"Quando a Serenidade em relação às coisas e abertura ao mistério se despertarem em nós, aí então poderemos esperar chegar a um caminho que conduza a um novo solo e fundamento. Neste fundamento, a criação de obras duradouras poderia lançar novas raízes." Martin Heidegger, Serenidade. 1994

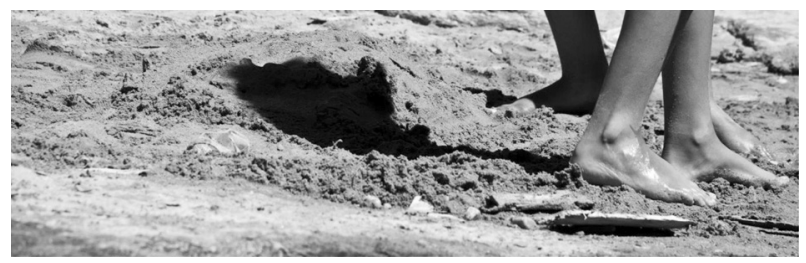




\section{Introdução}

Trago para este texto a proposta de pensar a arte através da fotografia e da poesia de Manoel de Barros como possibilidade reveladora das relações diversas do homem com a terra, ou seja, sua geograficidade. Mas antes de adentrar especificamente nesta questão, penso ser importante trazer à luz pontos de fundamento para ajudar a desvelar o contexto para dentro do qual pretendo trazer essa experiência/vivência com a fotografia e a poesia. Tal fundamento aponta para a própria geografia e, principalmente, para o significado de ser geógrafo.

O exercício do pensar geográfico nos coloca diante do desafio de procurar compreender "as relações homem-mundo" tendo disponível um universo temático diversificado e complexo. Mas que significam tais relações? De que maneira elas nos "afetam" e como reagimos a elas? Como podemos verdadeiramente compreender a dinâmica desta teia extremamente complexa quando muitos de nós buscam pelas respostas participando apenas como meros espectadores sem que estejamos efetivamente conscientes de que não só fazemos parte, mas efetivamente somos esta relação?

Outras tantas questões semelhantes fazem parte do universo em torno do qual é importante pensar uma vez que buscamos a construção de um fazer/pensar geográfico autêntico através da experiência/vivência. Para ajudar a construir este caminho em direção a uma maior autenticidade, nos apoiamos na fenomenologia. Como coloca Dal Gallo:

Adotar a fenomenologia significa em primeiro lugar, reconhecer que a base do conhecimento geográfico reside na experiência geográfica. Experienciar é ir ao encontro de algo e ser tocado por ele em um âmbito ontológico-existencial, pois esse encontro reivindica uma entrega, um comum-pertencer que articula intimamente aquilo que se encontra ou se reúne. (Dal Gallo, 2015, p. 82)

Como geógrafa penso hoje em uma geografia que nasça de nossa experiência aliada à demora e à pausa necessárias. Digo, penso hoje, em função de um desvelar tardio que somente com a fenomenologia me pus a parar e buscar por respostas a uma série de indagações que, pouco a pouco, me colocaram no caminho do pensar e a procurar por uma ontologia daquela que penso ser a geografia que busco: uma geografia que nasce da relação do homem com a terra, ou seja, a geograficidade poeticamente nomeada por Eric Dardel. (Dardel, 2011).

Começo esta experiência pela fotografia. O que procuro ver em uma fotografia está além da superfície como elucida Fluzzer (1985). É preciso um olhar "atravessante... mergulhador e explorador" que esteja disposto a não ficar apenas na superfície, que não se prenda apenas à materialidade retratada, mas que possa mergulhar mais fundo em busca não de uma (re)velação, mas do desvelamento, ou seja, que a fotografia possa nos levar na direção da clareira através da qual possamos entender a verdade do habitar.

Ao percorrer para além da superfície onde se mostram a aparência das coisas, várias imagens ocultas se revelam a partir daquela que nossos olhos inicialmente capturaram. Que possamos olhar uma fotografia com os olhos de "transver", como dizia o Mestre Manoel de Barros.

É preciso ressaltar que não consideramos a fotografia como reprodução mimética. Concordando com Heidegger, as reproduções e imitações são deformações da imagem propriamente. Penso a fotografia como um convite para que, direcionando nossos olhar para o invisível, sejamos capazes de participar de algo estranho. E que esta imagem poética imaginada não se trata de meras fantasias ou ilusões.

Imaginações entendidas não apenas como inclusões do estranho na fisionomia do que é familiar, mas também como inclusões passíveis de serem visualizadas. $\mathrm{O}$ dizer poético das imagens reúne integrando a claridade e a ressonância dos muitos aparecimentos celestes numa unidade com a obscuridade e a silenciosidade do estranho. (Heidegger, 1998, p. 177)

Para Deleuze (2007) tanto em pintura quanto em música, mas creio que se aplica também para o que defendemos na fotografia, não se trata de reproduzir, mas de captar forças. E esta força não está no que Fluzzer chama de superfície da fotografia, mas no "invisível” tornado visível.

O significado da imagem encontra-se na superfície e pode ser captado por um golpe de vista. No entanto, tal método de deciframento produzirá apenas o significado superficial da imagem. Quem quiser "aprofundar" o significado e restituir as dimensões abstraídas, deve permitir à sua vista vaguear pela superfície da imagem. (...) Ao vaguear pela superfície, o olhar vai estabelecendo relações temporais entre os elementos da imagem: um elemento é visto após o outro. O vaguear do olhar é circular: tende a voltar para contemplar elementos já vistos. Assim, o "antes” se torna “depois", e o “depois" se torna o "antes”. O tempo projetado pelo olhar sobre a imagem é o eterno retorno. (Fluzzer, 1985, p. 7)

Encontrei nas palavras de Cecília Meireles em um trecho de sua crônica "Da solidão" este mesmo "convite" feito por Fluzzer,

(...) Façamo-nos também desse modo videntes: olhemos devagar para a cor das paredes, o desenho das cadeiras, a transparência das vidraças, os dóceis panos tecidos sem pretensões. Não procuraremos neles a beleza que arrebata logo o olhar, o equilíbrio de linhas, a graça das proporções; muitas vezes seu aspecto, como o das criaturas humanas, é inábil e desajeitado. 
Mas não é isso que procuramos, apenas: é o seu sentido íntimo que tentamos discernir. Amemos nessas humildes coisas a carga de experiências que representam, e a repercussão, nelas sensível, de tanto trabalho humano, por infindáveis séculos. (...) (Meireles, 2003)

A fotografia sempre me possibilitou (re)encantar diante das coisas do mundo. Ela é para mim um convite à pausa proporcionada pelo "congelamento do tempo". Através desse "repouso" faço o convite para refletir sobre as coisas mesmas além do que foi ali capturado. Para seguir este caminho apoiamos no olhar/sentir/experienciar da fenomenologia. Vemos a fotografia como uma possibilidade de experiência não só para aquele que faz o registro, mas também para aquele que dele usufrui. Penso que através dela, de alguma maneira, a geograficidade própria do ser no mundo possa estar presente, tanto aquela vivenciada através dos sentidos como aquela imaginada.

$\mathrm{E}$, para trazer tudo isso à reflexão necessito trazer minha vivência com a fotografia que se aninha em parte na história de vida familiar. Cresci em uma casa natal onde havia um barracão nomeado de "barracão de fotografia". Trabalhando como repórter fotográfico da revista esportiva Placar, meu tio revelava naquele barracão as fotos tiradas durante uma tarde de partida de futebol no Mineirão e este momento era aguardado por mim, com certa ansiedade. Aquele era um lugar escuro... pintado de preto. A despeito de sua funcionalidade primeira, aquele espaço fora da casa era para mim um lugar. No seu interior havia um tanque, varais, mas principalmente aquela máquina responsável pelo momento mais aguardado: a revelação. Uma imagem que lentamente, após ser projetada, aparecia como mágica sobre um papel imerso em um líquido revelador.

Além de meu tio, seu cunhado, meu pai também gostava muito de fotografia, mas o olhar dele era outro. Se nas fotos de meu tio podíamos ver o campo de futebol lotado e jogadores em poses inesperadas, as de meu pai nos mostravam buracos de parede... fechaduras velhas... janelas de todas cores e formas. Criança que era não gostava de suas fotos, "só tem buraco de parede!" eu dizia. Hoje entendo meu pai...

Além deles, minha mãe também sempre teve uma relação com a fotografia, no começo como apreciadora e mais tarde, inicia sua aventura ao adquirir sua própria máquina. Nossas viagens sempre ficaram "guardadas" nas fotografias tiradas por eles. Em casa, pouco depois de cada viagem era hora da família se reunir para recordarmos através das imagens projetadas na parede da sala. A "estreia” por trás da objetiva só veio alguns anos depois, durante o curso de geografia. Os trabalhos de campo sempre foram um bom motivo para fotografar: mesmo que, no princípio, apenas para compor um relatório de campo.

Durante o curso, o estilo se revela diante de um comentário comum: "em suas fotos quase nunca aparecem pessoas!”. Essa foi uma característica de minhas fotos há até pouco tempo. Um olhar direcionado prioritariamente para as características bio-fisicas das paisagens. E assim foi durante muitos anos com a fotografia, um olhar que evitava as pessoas. Sempre tivemos uma ligação forte com a terra, mas hoje sei que era uma "terra apartada". Mas este sentimento se transformava ao chegar em uma comunidade pequena e me encontrar com as pessoas do lugar cuja raiz na terra sempre me pareceu mais verdadeira. Que fique registrado que são impressões de um passado dentro qual pouco espaço havia para as reflexões que busco e que trago hoje.

Outro aspecto que gostaria de destacar é com relação às características do tipo de fotografias feitas. Geralmente, eram obtidas em cor, principalmente quando o interesse se voltava para as paisagens, mas quando o olhar mirava as pessoas, o registro se transformava em preto e branco. De uma maneira intuitiva retratava as pessoas em preto e branco por achar que este tipo de fotografia poderia estar captando além da aparência externa das coisas, indo mais profundamente, sendo capaz de registrar sua "alma". Mais uma vez, meu olhar pedia algo mais do que foi registrado pela simples reflexão da luz gravada na película.

Mais tarde, ao participar de projeto desenvolvido em uma comunidade quilombola - Moça Santa no Vale do Jequitinhonha, novamente a fotografia adquiriu um papel importante no meu trabalho. O objetivo era fazer o registro de uma oficina ministrada por uma ceramista e as mulheres de Moça Santa (Figura 1).

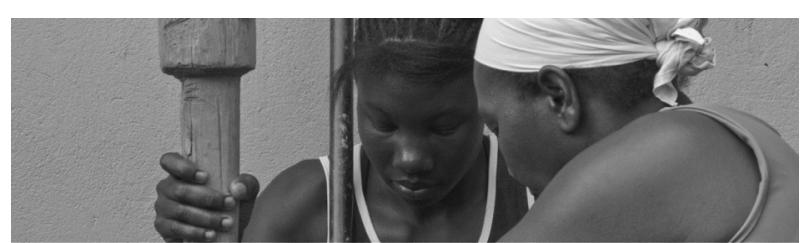

Figura 1: Mulheres da comunidade quilombola de Moça Santa preparando o barro.

Num primeiro momento, o objetivo era resgatar o gosto por "tecer o barro" na comunidade, uma vez que em um passado distante Moça Santa foi lugar de paneleiras. Neste trabalho meu olhar se transformou. As fotografias passaram a registrar o "mundo da vida" onde as mulheres aparecem em diferentes momentos como a construção do forno para queimar as peças, a extração do barro, além do registro do Curiango que é uma cantiga de roda com as mulheres, onde elas cantam e dançam com os pés no chão (Figura 2).

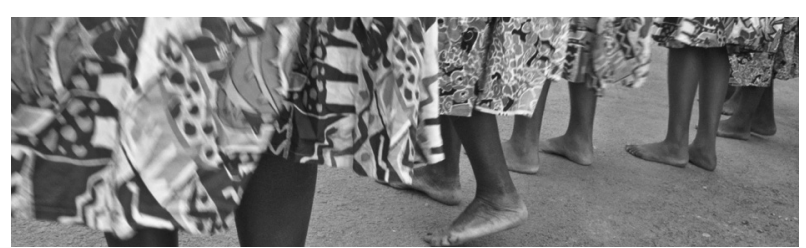

Figura 2: Mulheres durante o Curiango, dança típica do Vale do Jequitinhonha-MG. 
Em um momento mais recente, já em contato com a fenomenologia e seus autores, uma passagem do texto Poeticamente... o homem habita de Heidegger nos fez pensar na fotografia não só como uma linguagem, mas como possibilidade poética. Mesmo sua fala sendo dirigida ao poeta, penso que se aplicaria também ao fotógrafo-poeta:

Quanto mais poético um poeta, mais livre, ou seja, mais aberto e preparado para a colher o inesperado é o seu dizer; com maior pureza ele entrega o que diz ao parecer daquele que o escuta com dedicação, é maior a distância que separa o seu dizer da simples proposição, esta sobre a qual tanto se debate, seja no tocante à sua adequação ou à sua inadequação. (Heidegger, 2012, p. 168)

Linguagem que seja a "fala” derivada da experiência geográfica, que concordando com Besse, é primeiramente se colocar como presença afetiva com a singularidade de um lugar e de uma fisionomia portadora de significado. É se deixar levar pela tonalidade do lugar (Besse, 2011) (Figura 3).

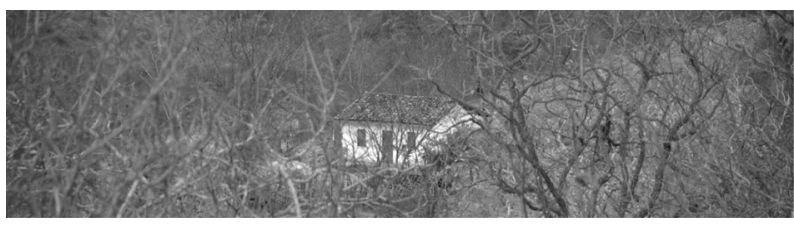

Figura 3: Tonalidades que nos remetem a imagem do habitar em algum ponto no vale do Jequitinhonha-MG.

Diante disso, nos resta questionar se a linguagem científica e objetiva a que estamos acostumados seria capaz de trazer à clareira o habitar do ser. Assim

Numa concepção de ciência que busque o desvelamento do ser, busca-se uma linguagem que busque menos em objetificar aquilo que se mostre, mas que dê condições de elucidar como aquilo que se mostra poder se mostrar. Isso levou Heidegger a se aproximar do poético, com a arte e com a superação da metafísica através da ontologia. (Dal Gallo, 2015 p. 16)

A linguagem poética exige que tenhamos uma postura diferente diante do modo em que estamos e somos o/no mundo. Que tenhamos olhos, ouvidos não convencionais, pois é uma linguagem com significados vários e, portanto para que consigamos escutar algo sobre a saga do dizer poético, como nos fala Heidegger (2003), não podemos ir ao seu encontro guiados pela "busca surda" de um sentido unívoco.

E a arte, por sua linguagem poética, possibilitaria segundo Del Gallo (2015, p. 20) "retirar os objetos de sua concepção prática e utilitária resultante de um longo contato habitual e os colocaria em uma situação de estranheza causando uma ruptura com a existência cotidiana”. E foi esta condição de estranheza proporcionada pela proximidade tanto pela fotografia que nos colocou em um lugar diferente daquele que habitualmente costumamos estar. Desde então, ela tem sido forte aliada como forma de manifestar nossa relação com o mundo (Figura 4).

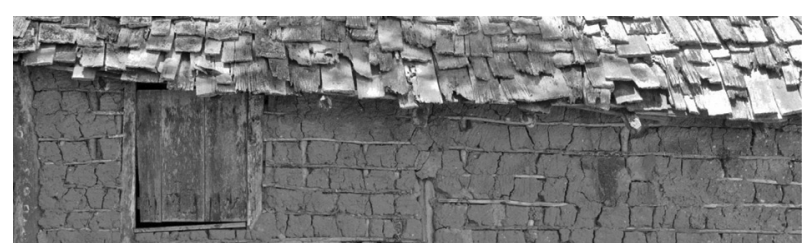

Figura 4: Para além de uma simples cabana de pescador.

Mas para esta tarefa foi preciso chegar ao ponto de pausa para a escuta necessária (Figura 5). Escuta derivada do que tem sido essa experiência com a geografia e a arte. E retomo aqui, pedindo licença a Jorge Larrosa Bondiá, um trecho de um texto seu que, de maneira clara, ajudou a entender um pouco mais deste momento:

A experiência, a possibilidade de que algo nos aconteça ou nos toque, requer um gesto de interrupção, um gesto que é quase impossível nos tempos que correm: requer parar para pensar, parar para olhar, parar para escutar, pensar mais devagar, olhar mais devagar, e escutar mais devagar; parar para sentir, sentir mais devagar, demorar-se nos detalhes, suspender a opinião, suspender o juízo, suspender a vontade, suspender o automatismo da ação, cultivar a atenção e a delicadeza, abrir os olhos e os ouvidos, falar sobre o que nos acontece, aprender a lentidão, escutar aos outros, cultivar a arte do encontro, calar muito, ter paciência e dar-se tempo e espaço. (Bondiá, 2002, p. 24)

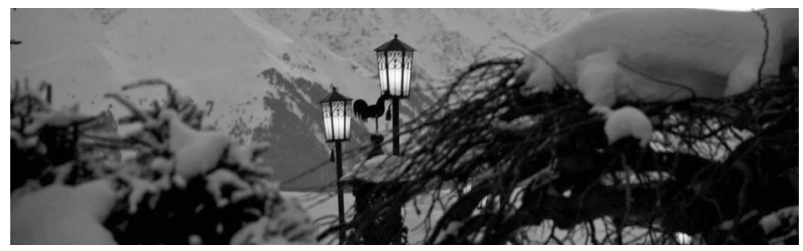

Figura 5: Pausar para suspender o aparentemente óbvio.

Assim também nos alerta Win Wenders no documentário Janela da Alma em relação à necessidade de estarmos atentos não apenas ao tempo que nos escapa, mas também ao bombardeio de imagens a que somos expostos e que nos furta a capacidade de nos emocionarmos. Para ele, a quantidade de imagens significa basicamente que somos incapazes de prestar atenção e de nos emocionarmos com as imagens. Atualmente, as estórias tem que ser extraordinárias para nos comoverem, pois não conseguimos mais ver as histórias simples.

A fotografia foi o ponto de partida. Neste caminhar nos aproximamos também da imagem revelada pelas palavras encantadas e encantadoras de Manoel de Barros, poeta pantaneiro que registrou em suas poesias "crianceiras", 
as paisagens, os lugares e sua gente (Figura 6). Registros estes, que testemunham uma vida vivida em meio a tantas coisas "desimportantes" que foram fundamentais na construção de sua relação com os outros e com o mundo.

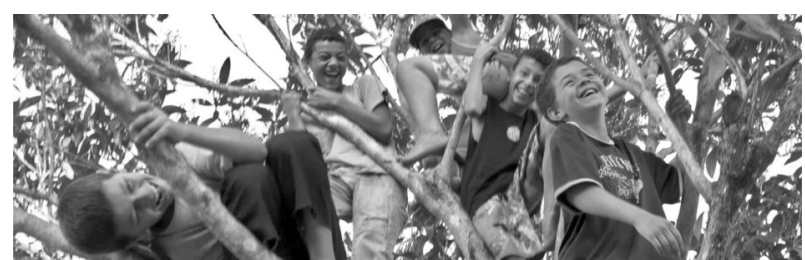

Figura 6: Junto às crianças estão as palavras do poeta Manoel de Barros.

Mas são estas "coisas", de importância questionada por tantos é que o marcaram e que anunciam, através de um "festejo de linguagem", a sua relação íntima e de cumplicidade com o mundo. Assim, inspirada por seu poema O FOTÓGRAFO, encontro minha sustentação poética para, através de sua fala, afirmar o que penso da fotografia: de que nela busco a força do invisível sabiamente escondido para o desvelamento da condição humana do existir.

Difícil fotografar o silêncio.

Entretanto tentei. Eu conto:

Madrugada, a minha aldeia estava morta. Não se via ou ouvia um barulho, ninguém passava entre as casas. Eu estava saindo de uma festa.

Eram quase quatro da manhã. Ia o silêncio pela rua carregando um bêbado. Preparei minha máquina.

O silêncio era um carregador?

Estava carregando o bêbado.

Fotografei esse carregador.

Tive outras visões naquela madrugada. Preparei minha máquina de novo. Tinha um perfume de jasmim no beiral do sobrado. Fotografei o perfume.

Vi uma lesma pregada na existência mais do que na pedra.

Fotografei a existência dela.

Vi ainda um azul-perdão no olho de um mendigo. Fotografei o perdão.

Olhei uma paisagem velha a desabar sobre uma casa. Fotografei o sobre.

Foi difícil fotografar o sobre. Por fim eu enxerguei a nuvem de calça.

Representou pra mim que ela andava na aldeia de braços com Maiakoviski - seu criador. Fotografei a nuvem de calça e o poeta.

Nenhum outro poeta no mundo faria uma roupa mais justa para cobrir sua noiva.

A foto saiu legal.

(Barros, 2010 p. 377)

Sua escrita simples, mas que ao mesmo tempo pede calma e reflexão profundas, foi relevante neste despertar e mostrou o sempre buscado: a autenticidade que como as coisas mostradas pelo poeta, estão bem "escondidas" precisando apenas que sejam encontradas com a ajuda de um olhar mais cuidadoso.

Manoel de Barros nos permitiu enxergar tudo isso juntamente com outros tantos filósofos/pensadores. Foi ele que nos ajudou a entender, por exemplo, através de seu poema MIRÓ o que penso queria Husserl com sua redução ou mesmo Heidegger ao dizer em relação à arte. Assim fala o poeta:

Para atingir sua expressão fontana Miró precisava de esquecer os traços e as doutrinas que aprendera nos livros.

Desejava atingir a pureza de não saber mais nada.

Fazia um ritual para atingir essa pureza: ia ao fundo do quintal à busca de uma árvore.

E ali, ao pé da árvore, enterrava de vez tudo aquilo que havia aprendido nos livros.

Depois depositava sobre o enterro uma nobre mijada florestal.

Sobre o enterro nasciam borboletas, restos de insetos, cascas de cigarra etc.

A partir dos restos Miró iniciava a sua engenharia de cores.

Muitas vezes chegava a iluminuras a partir de um dejeto de mosca deixado na tela.

Sua expressão fontana se iniciava naquela mancha escura.

O escuro o iluminava.

(Barros, 2010 p. xxx)

Com Manoel de Barros foi possível compreender o que Heidegger nos apresenta através das palavras de outro poeta, Friedrich Hölderlin: Precisamos nos fazer poeta para que algo se desvele e venha finalmente para a luz, precisamos poetar para que o "habitar autêntico", ou seja, um habitar sobre a terra, sob o céu e à vista dos seres divinos esteja ao alcance de quem assim o desejar (Figura 7).

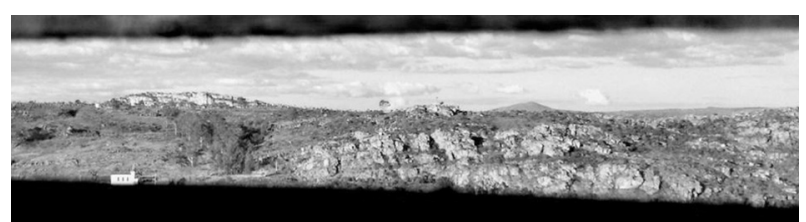

Figura 7: Entre o céu e a terra, junto às divindades e com os mortais, habitamos o mundo.

Escuta na pausa proporcionada pela nossa experiência nos faz ver que não só a fotografia, mas também a poesia de Manoel de Barros se revelou como possibilidade de um caminho para a "expressão" da geograficidade, principalmente aquela experienciada no espaço telúrico de Eric Dardel, capaz de, através da experiência sensorial, nos colocar em contato com a substância antes de se transformar em idéias e noções. 
Assim foi na companhia de todos eles e de suas imagens que, aos poucos fomos percebendo um caminho além daquele desvelado no início pela fotografia... nos fez desejar o caminho da Geopoética, da linguagem poética...da arte. E o que se mostra agora é que a fotografia não pode ser o único foco, ela é apenas uma das pontas para revelar a realidade geográfica de Dardel que é a dos lugares onde estamos, dos lugares de nossa infância, dos nossos deslocamentos compostos por sons, cheiros, cores, sabores, sentimentos, lembranças... memórias.

Por tudo isso, este texto busca ajudar a pensar sobre o papel das artes, principalmente a fotografia junto à poesia de Manoel de Barros, como aliada no desvelar de um habitar poético. Trago, portanto, um convite à reflexão nas palavras de Benedito Nunes,

O pensamento de hoje, mais calculista e previsor, prepara-se para deixar a habitação terrestre em demanda de uma habitação cósmica - o "espaço esvaziado do mundo", que, no entanto, continuaria sendo para aqueles eventuais astronautas ainda susceptíveis de experimentar o ancestral sentimento de admiração e estranheza. (Nunes, 2000 p. 126)

Mas não só os sentimentos propriamente ditos, como objeto de preocupação, mas no que tais sentimentos podem despertar para que verdadeiramente possamos acordar para nossa condição terrestre de habitantes, no seu sentido mais originário. Estamos e somos a terra que habitamos.

Peço licença para terminar com tudo que trago em mim agora. Poeticamente, adjunto adverbial de modo de habitar!...

Poética na mente...

Brincadeira como forma de habitar...

Na brincadeira a criança habita poeticamente...

A fotografia como possibilidade poética...

Fotografando... o homem habita...

Brincadeira... fotografia e poesia como modo de habitar...

Brincando com as palavras o poeta Manoel de Barros habitou...

Geograficidade - propriedade de habitarmos poeticamente o mundo...

\section{Referências}

Barros, M. (2013). Poesia completa. São Paulo: LeYa.

Besse, J. M. (2011). Geografia e Existência: A Partir da Obra de Eric Dardel. O homem e a Terra: natureza da realidade geográfica. (W. Holzer, Trad.). São Paulo: Editora Perspectiva.

Bondía, J. L. (2002). Notas sobre a experiência e o saber de experiência. Revista Brasileira de Educação. Jan/Fev/Mar/Abr, (19), 20-28.
Dardel, E. (2011). O homem e a Terra: natureza da realidade geográfica. (W. Holzer, Trad.). São Paulo: Editora Perspectiva.

Deleuze, G. (2007). Francis Bacon: lógica da sensação. (R. Machado [Coord.]. Trad.). Rio de Janeiro: Zahar.

Flusser, W. (1985). Filosofia da caixa preta: ensaios para uma futura filosofia da fotografia. São Paulo: Hucitec.

Heidegger, M. (2010). A origem da obra de arte (I. Azevedo e M. A. De Castro, Trad.). São Paulo: Edições 70.

Heidegger, M. (2012c). Poeticamente o homem habita. Em Heidegger, M. Ensaios e Conferências. (E. C. Leão, G. Fogel, M. S. C, Schuback, Trad.). Petrópolis, RJ: Vozes; Bragança Paulista, SP: Editora Universitária São Francisco. P 165-181.

Heidegger, M. (2003). A caminho da linguagem (M. S. C, Schuback, Trad.). Petrópolis-RJ: Vozes, Bragança Paulista, SP: Editora Universitária São Francisco.

Heidegger, M. (1994). Serenidade (M. P. L. Viera, Trad.) da versão castelhana de Yves Zimmermann publicado pela Ediciones del Serbal, Barcelona, Janela da Alma. Direção de João Jardim e Walter Carvalho. Brasil, 2002.

Meireles, C. (2003). Da solidão. Disponível em: < http://oninhoeatempestade.blogspot.com.br/2009/02/da-solidao-ceciliameireles.html>.

Nunes, B. (2000). Heidegger e a poesia. Natureza Humana, 2(1):103-127 .

Valéria Amorim do Carmo - Possui Graduação, Mestrado e Doutorado em Geografia pela Universidade Federal de Minas Gerais. Professora do Instituto de Geociências da Universidade Federal de Minas Gerais; Pesquisadora do Núcleo de Pesquisa em Geografia Humanista - NPGEOH, do Grupo Geografia Humanista Cultural - GHUM, do Grupo de Pesquisa Fenomenologia e Geografia - NOMEAR, e do Grupo Geografia Humanista, Arte e Psicologia Fenomenológica - GhuAPo. Endereço Institucional: Rua Itapema, 105 apto. 901, Bairro Anchieta, CEP: 30 310-490, Belo Horizonte - Minas Gerais. E-mail: vamorimbh@gmail.com

Recebido em 03.05.16 Primeira Decisão Editorial em 25.07.16 Aceito em 29.08.16 